\title{
CORRIGENDUM
}

\section{Perinatal undernutrition programmes thyroid function in the adult rat offspring - CORRIGENDUM}

\author{
Rosario Ayala-Moreno, Radu Racotta, Brenda Anguiano, Carmen Aceves and Lucía Quevedo \\ (First published online 13 August 2013)
}

doi:10.1017/S0007114513001736, Published by Cambridge University Press, June 2013.

The author regrets to announce that there is a mistake in Fig. 2 of this $\operatorname{article~}^{(1)}$.

In the graph that appears at the left in the bottom panel, the title of the ordinate axis should be 'Free $\mathrm{T}_{4}$ ' instead of 'Free $\mathrm{T}_{3}$ '.

The corrected figure is published here.
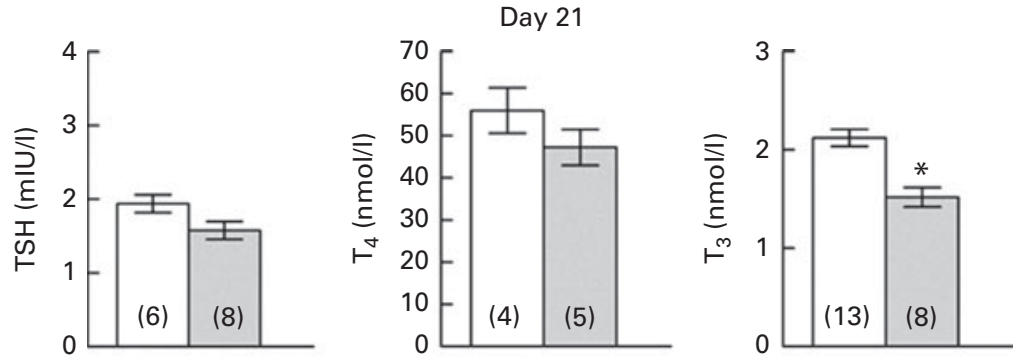

Day 90
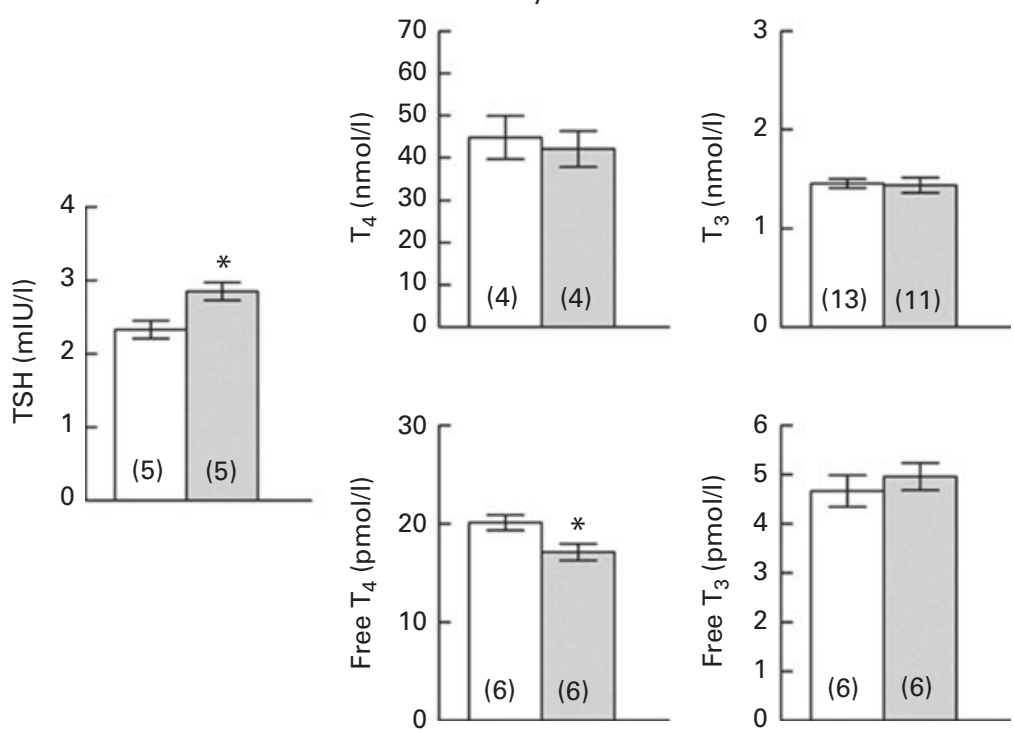

Fig. 2. Effects of undernutrition on plasma thyrotropin (TSH), thyroxine $\left(T_{4}\right)$ and $3,5,3^{\prime}$-triiodothyronine $\left(T_{3}\right)$ levels in the female offspring (postnatal day 21 ) and free $T_{4}$ and free $T_{3}$ levels in adult rats (postnatal day 90 ). Values are means of the control ( $\square$ ) and $40 \%$ food-restricted ( $\square$ ) rats, with their standard errors represented by vertical bars. Numbers of rats per group are shown in parentheses. * Mean values were significantly different from those of the control group $(P<0.05$; Student's $t$ test).

\section{Reference}

1. Ayala-Moreno R, Racotta R, Anguiano B, et al. (2013) Perinatal undernutrition programmes thyroid function in the adult rat offspring. Br J Nutr 1-9, (Epub ahead of print). Published by Cambridge University Press, June 2013, doi:10.1017/S0007114513001736. 